\title{
Fast Determination of Sudan I by HPLC/APCI-MS in Hot Chilli, Spices, and Oven-Baked Foods
}

\author{
F. TATEO* AND M. BONONI \\ Laboratori di Ricerche Analitiche sugli Alimenti, Dipartimento di Produzione Vegetale, \\ Università degli Studi di Milano, Via Celoria, 2 - 20133 Milano, Italy
}

\begin{abstract}
The Commission Decision of EC dated 20 June 2003, on emergency measures concerning hot chilli and hot chilli products coming into any EC member state, required that the consignments of such products should be accompanied by an analytical report showing that they are free of artificial dye Sudan I. The opportunity to set a confirmatory method is evident, and the paper proposes a HPLC/ APCI-MS method useful for identification and quantitation of Sudan I, also at very low levels in hot chilli, other spices, and oven-baked foods. Validation data are reported.
\end{abstract}

KEYWORDS: Sudan I; dye; colorant; hot chilli; oven-baked products

\section{INTRODUCTION}

The Commission Decision of EC dated 20 June 2003 on emergency measures regarding hot chilli products (1) establishes various measures concerning the analytical control of hot chilli and hot chilli products at import or already on the market. More precisely the Decision applies to fruits of the genus Capsicum, dried and crushed or ground.

To protect public health, it is required that the consignments of the products above cited imported into the Community, in whatever form, and to use for human consumption should be accompanied by an analytical report demonstrating that the consignment does not contain the artificial dye Sudan I (1-phenylazo-2-naphthol, CAS 842-07-09) (Figure 1). The same decision suggests that it is appropriate to order destruction of adulterated hot chilli and hot chilli products to avoid their introduction into the food chain.

In the absence of such an analytical report, the importer established in the community shall have the product tested to demonstrate that it does not contain Sudan I, and pending availability of the analytical report, the product shall be detained under official supervision.

Sudan I has been classified as a category 3 carcinogen by the IARC (International Agency for Research on Cancer) as reported in the text of emergency measures previously mentioned.

The opportunity to set a confirmatory method is evident.

Sudan I has been utilized as internal standard in previous papers $(2-4)$ concerning the detection of carotenoids, and acetonitrile has been used as solvent. A method recently used (5) in a Regional Agency for Prevention and Environment suggests toluene as extraction solvent of Sudan I from chilli, re-dilution in methanol $80 \%$ of the dried extract, and methanol $100 \%$ as HPLC mobile phase on C18 column. In this case, GC/ MS is suggested to confirm the identity of the peak. The conditions suggested by OSHA ( 6 ) are the following: benzene

* To whom correspondence should be addressed. Tel. +39.02 .50316540 . Fax: +39.02.50316539. E-mail: fernando.tateo@unimi.it.

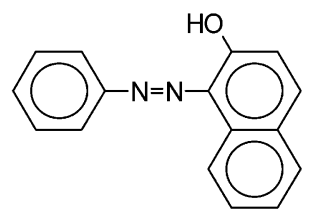

Figure 1. Structure of Sudan I (1-phenylazo-2-naphthol, CAS 842-0709).

for extraction, HPLC on C18 column, and methanol $100 \%$ as mobile phase, det. $\lambda=436 \mathrm{~nm}$.

Another method (7) proposed for determination of synthetic food colorants is based on HPLC technique coupled with a Dionex AD20 absorbance detector and for determination of colorant matters mixtures, including Sudan I, the technique of solid-phase spectrophotometry (8) has been also applied.

A collaborative trial from Food Standards Agency $(9,10)$ shows two methods, $145 \mathrm{a}$ and $145 \mathrm{~b}$, concerning the application of HPLC to evaluate Sudan I in chilli powder.

Considering that the methods available today for the detection of natural and not natural coloring substances are based on HPLC/DAD techniques using the UV-vis spectrum to confirm peak identity, it is opportune to define an analytical method that could permit the identification of Sudan I with more certainty. In extracts produced from foods containing Sudan I at levels of few $\mathrm{mg} / \mathrm{kg}$ and other natural $/$ not natural coloring substances, the low amounts often do not allow to quantify the HPLC peaks area and to use UV-vis spectra as discriminant index.

This note reports data showing the efficiency of the HPLC/ APCI-MS method for determination of Sudan I at very low levels in hot chilli and in foods as oven baked products, for example "hot taralli" widely used in Italy.

\section{MATERIALS AND METHODS}

Samples and Chemicals. The experiments were conduced on dried hot chilli (both ground and powder), turmeric, and paprika, deriving from the ones sent to the Laboratory for analytical control.

The oven-baked product "taralli", often containing chilli powder or ground chilli, were also considered as representative of the presence of the forbidden coloring substance in the food chain. 

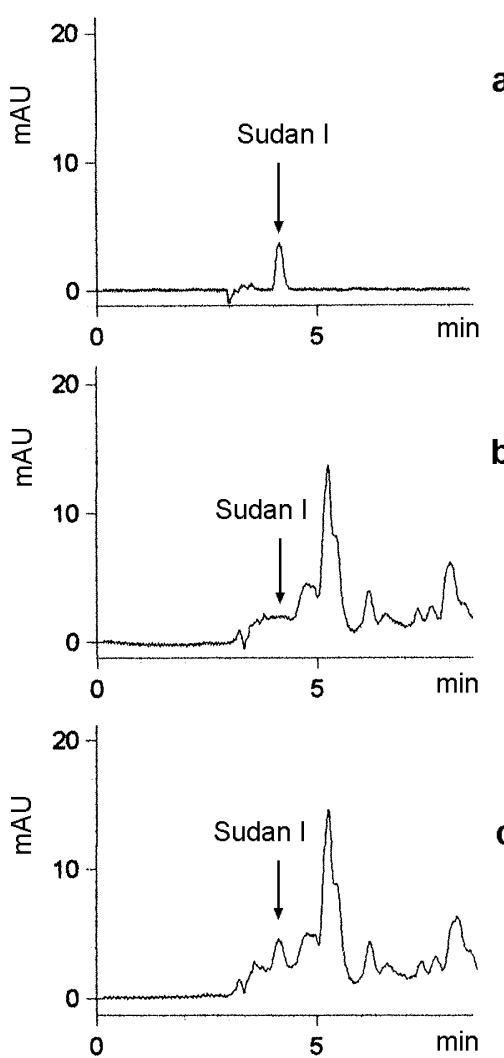

Figure 2. HPLC elution profile of (a) standard solution of Sudan I at 489 $\mu \mathrm{g} / \mathrm{L}$, (b) ethanolic extract from a sample of commercial genuine "hot chilli", and (c) ethanolic extract at $391 \mu \mathrm{g} / \mathrm{L}$ deriving from the same "hot chilli" enriched with Sudan I at $9.59 \mathrm{mg} / \mathrm{Kg}$. The detection was performed at $\lambda=481 \mathrm{~nm}$.

The extractant used for sample preparation was ethanol 96\% (Merck, code 100971), and the standard was Sudan I (97\%, Sigma-Aldrich inc., code $10,362-4)$.

The solvents for chromatography were HPLC grade methanol (Sigma-Aldrich) and acetonitrile (BDH).

Sample Preparation. (A) Extraction Procedure from Hot Chilli. The sample is finely ground by an electric blender, and an amount of about $1 \mathrm{~g}$, exactly weighted, is shaken for $20 \mathrm{~min}$ with $20 \mathrm{~mL}$ of ethanol $96 \%$ and then stirred in an ultrasonic bath for $10 \mathrm{~min}$. The extraction is repeated three times, every time recovering the liquid phase after filtration on sodium sulfate anhydrous. The extract, collected in a sealed flask, is concentrated under vacuum in rotary evaporator up to about $10 \mathrm{~mL}$, transferred into a $25-\mathrm{mL}$ volumetric flask and then diluted to volume with washing ethanol $96 \%$.

(B) Extraction Procedure from Oven-Baked Products. The sample was finely ground by an electric blender, and an amount of $50 \mathrm{~g}$, exactly weighted, was shaken for $20 \mathrm{~min}$ with $100 \mathrm{~mL}$ of ethanol $96 \%$ and then stirred in an ultrasonic bath for $10 \mathrm{~min}$. The extraction is repeated three times, every time recovering the liquid phase after filtration on sodium sulfate anhydrous. The extract, collected in a sealed flask, is concentrated under vacuum in a rotary evaporator up to about $10 \mathrm{~mL}$, transferred into a $25-\mathrm{mL}$ volumetric flask and then diluted to volume with washing ethanol $96 \%$. The extract, so obtained, is filtered again before injection.

HPLC. HPLC Shimadzu system (Shimadzu Italia srl, Milan, Italy) was used, consisting of the following: (a) System Controller SCL10Avp; (b) two pumps LC-10ADvp; (c) Rheodyne injection valve (7725i, $20 \mu \mathrm{L}$ loop); (d) Diode Array Detector SPD-M10Avp performing detection at $\lambda=481 \mathrm{~nm}$; (e) acquisition software Class VP-5Shimadzu, and an RP-Amide (C16) column (4.6-mm $\times 250-\mathrm{mm}$, $5-\mu \mathrm{m}$, Supelco, Bellefonte, PA - code 505064). The mobile phase is acetonitrile (A) and methanol (B).

The operating conditions were as follow: 8 min isocratic A 70\%, followed by a gradient to $100 \% \mathrm{~B}$ in $10 \mathrm{~min}$. To reequilibrate, $10 \mathrm{~min}$

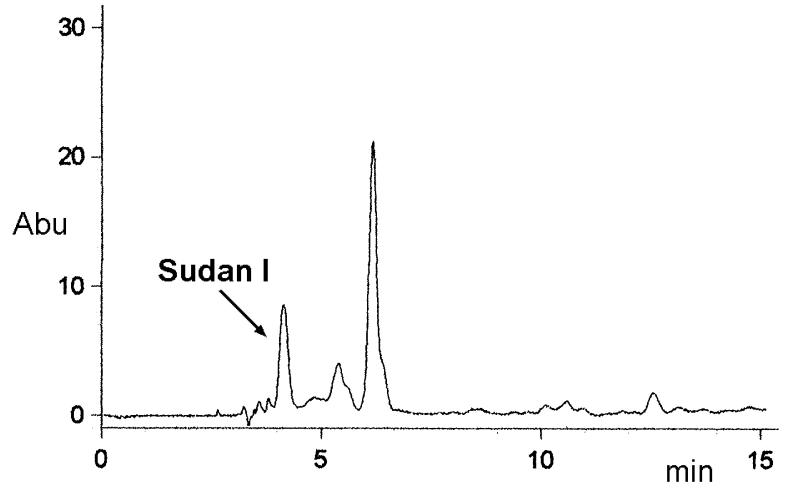

Figure 3. HPLC elution profile of an extract containing $1149 \mu \mathrm{g} / \mathrm{L}$ of Sudan I obtained with the procedure B from a commercial sample of "taralli". The amount of Sudan I in this sample was $972 \mu \mathrm{g} / \mathrm{Kg}$. The detection was performed at $\lambda=481 \mathrm{~nm}$.

isocratic B $100 \%$ followed first by a gradient to $60 \%$ B in 2 min and then to $30 \% \mathrm{~B}$ in $5 \mathrm{~min}$. The flow rate was $1 \mathrm{~mL} / \mathrm{min}$ and $20 \mu \mathrm{L}$ of ethanolic extract was injected. The retention time ranges from 4.1 to $4.3 \mathrm{~min}$.

HPLC/APCI-MS. An HPLC system (Shimadzu Italia srl, Milan, Italy) was used, consisting of the following: (a) System Controller (SCL10Avp); (b) one pump LC-10ADvp; (c) Rheodyne injection valve (7725i, $20 \mu \mathrm{L}$ loop); (d) acquisition software LCMS-Solution Version 2.02 Su 1 Shimadzu, and an RP-Amide (C16) column (4.6-mm $\times$ 250-mm, 5- $\mu \mathrm{m}$, Supelco, Bellefonte, PA - code 505064). The mobile phase was methanol at a flow rate of $1 \mathrm{~mL} / \mathrm{min}$, and $20 \mu \mathrm{L}$ of ethanolic extract was injected.

The HPLC system is coupled with a LCMS-QP8000 $\alpha$ quadrupole mass spectrometer (Shimadzu Italia srl, Milan, Italy) equipped with an APCI (Atmospheric Pressure Chemical Ionization) ionization source. The APCI probe is heated to $400{ }^{\circ} \mathrm{C}$ to ensure complete vaporization of the column effluent. The CDL (curved desolvation line) temperature is $250{ }^{\circ} \mathrm{C}$, source voltage $2,4 \mathrm{kV}$ and the gas flow $2,5 \mathrm{~L} / \mathrm{min}$. The acquisition mode was MID (multiple ion detector) monitoring ions $\mathrm{m} / \mathrm{z}$ 248,249 , which correspond to $[\mathrm{M}]^{+}$and $[\mathrm{M}+1]^{+}$, respectively. The peak quantitation was made on TIC of the two ions.

For experiences by HPLC/DAD and by HPLC/APCI-MS, the external standard method was used: the calibration curve was made from standard solutions of Sudan I (97\%, Sigma-Aldrich Inc., code $10,362-4$ ), ranging from 0.098 to $9.778 \mathrm{mg} / \mathrm{L}$ (ppm) in ethanol and injecting $20 \mu \mathrm{L}$.

\section{RESULTS AND DISCUSSION}

The efficiency of the HPLC/DAD method was verified for identification and quantitation of Sudan I both in hot chilli and in hot "taralli", using the two extraction methods A and B, respectively. Following extraction procedure A, the detection limit was $5 \mathrm{mg} / \mathrm{kg}$ of sample, and the quantitation limit was assumed as $15 \mathrm{mg} / \mathrm{kg}$ of sample (i.e., 3 times the detection limit). Recovery values ranged from 98 to $105 \%$ and CV\% from 12 and 4 (spiking made at levels between 15 and $300 \mathrm{mg} / \mathrm{kg}$ to a chilli sample Sudan I free).

Following extraction procedure $\mathrm{B}$ the detection limit was 80 $\mu \mathrm{g} / \mathrm{kg}$ and the quantitation limit was $240 \mu \mathrm{g} / \mathrm{kg}$ (i.e., 3 times the detection limit). Recovery values ranged from 73 to $78 \%$ and CV\% from 10 to 4 (spiking made at levels between 0.1 and $10 \mathrm{mg} / \mathrm{kg}$ to an oven baked sample Sudan I free).

The calibration curve was linear $\left(R^{2}=0.9980\right)$ in the range considered.

Figure 2 shows a comparison between the HPLC elution profile of (a) standard solution of Sudan I at $489 \mu \mathrm{g} / \mathrm{L}$, (b) ethanolic extract from a sample of commercial genuine "hot chilli", and (c) ethanolic extract at $391 \mu \mathrm{g} / \mathrm{L}$ deriving from the same "hot chilli" enriched with Sudan I at $9.59 \mathrm{mg} / \mathrm{kg}$. Figure 3 shows the HPLC elution profile of an extract containing 1149 


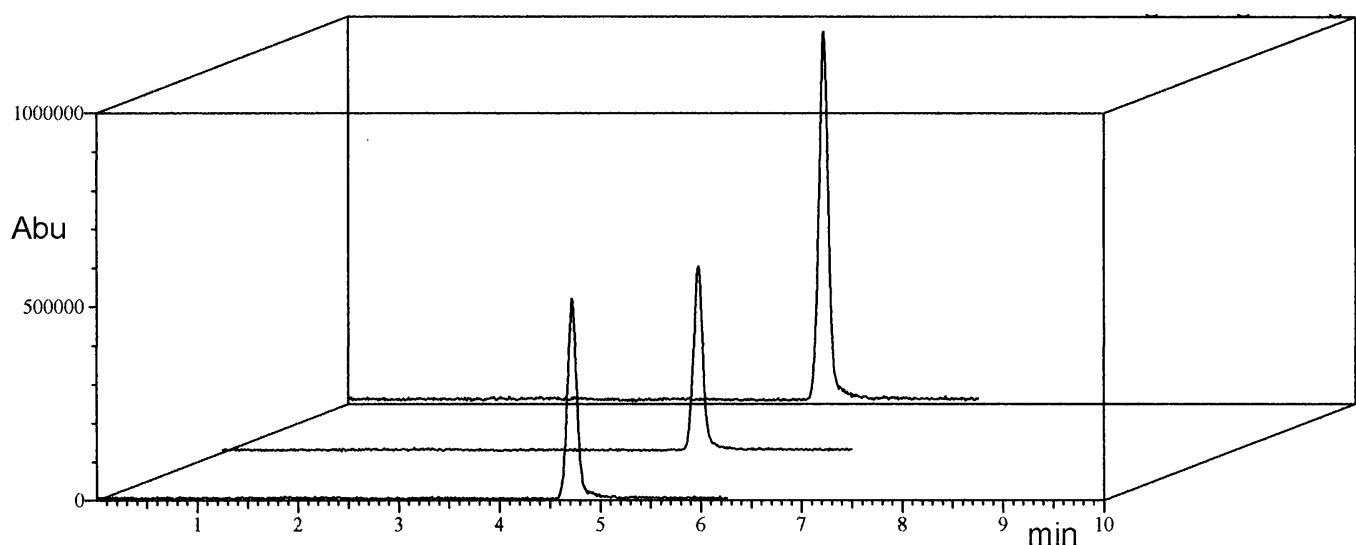

a

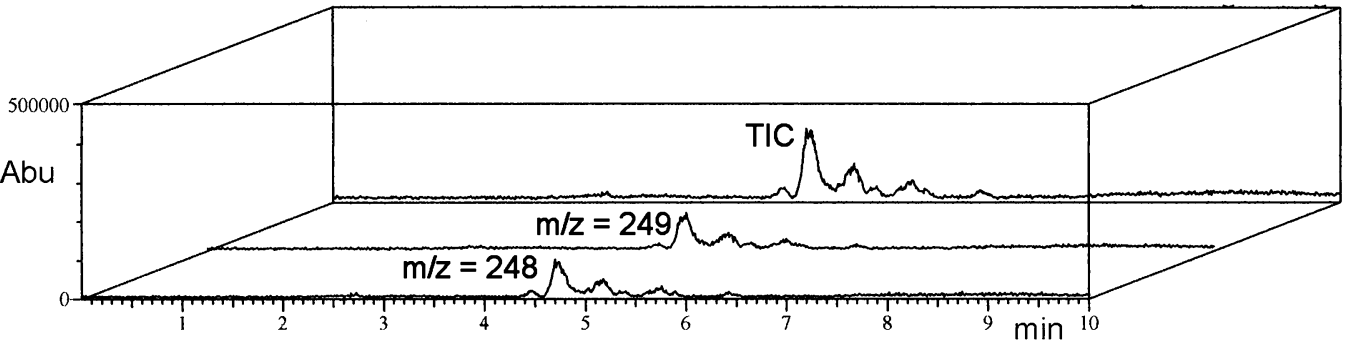

b

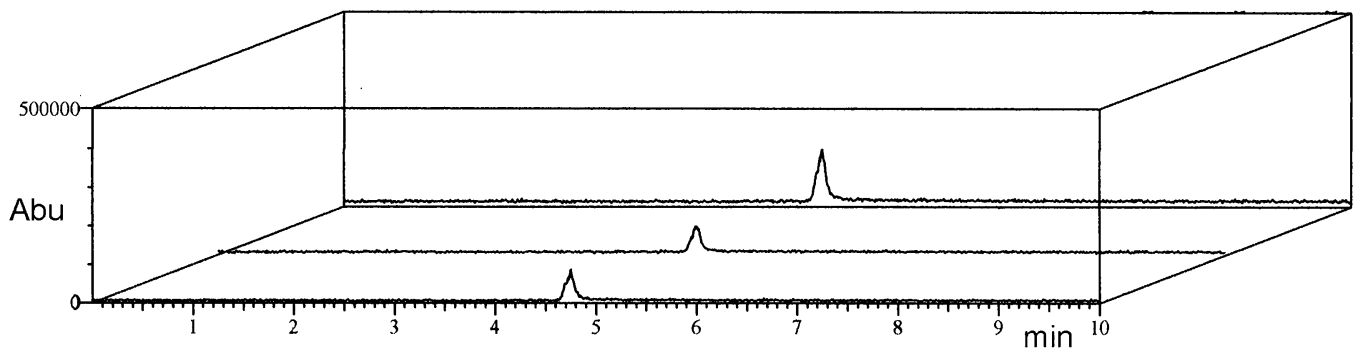

C

Figure 4. HPLC/APCI-MS elution profiles of (a) standard solution at $684 \mu \mathrm{g} / \mathrm{L}$, (b) extract of a sample of "taralli", obtained with the procedure B (see "Sample preparation") and diluted 10 times, (c) standard solution at $98 \mu \mathrm{g} / \mathrm{L}$. The amount of Sudan I in the sample of "taralli" was $968 \mu \mathrm{g} / \mathrm{kg}$. The acquisition mode was multiple ion detector (MID) monitoring ions $\mathrm{m} / \mathrm{z} 248$, and 249 , which correspond to [M] $]^{+}$and $[\mathrm{M}+1]^{+}$. The peak quantitation was made on TIC of the two ions.

$\mu \mathrm{g} / \mathrm{L}$ of Sudan I obtained from a commercial sample of "taralli". The amount of Sudan I in the sample resulted to be $972 \mu \mathrm{g} / \mathrm{kg}$, value corrected for dilution factor and recovery.

For some spices (i.e., paprika, turmeric) the application of HPLC/DAD method can be affected by inteferences and the identification and quantification by HPLC/APCI-MS described below results absolutely preferable.

To evaluate lower levels and to confirm the identity of the peak, also in cases where some interferences are evident, the use of HPLC/APCI-MS system is shown to be really opportune. For the extraction procedure A, the detection limit was $3 \mathrm{mg} /$ $\mathrm{kg}$ of sample, and the quantitation limit was assumed as $9 \mathrm{mg} /$ $\mathrm{Kg}$ of sample (i.e., 3 times the detection limit). Recovery values ranged from 85 to $100 \%$ and $\mathrm{CV} \%<3$ (spiking made at levels between 10 and $30 \mathrm{mg} / \mathrm{kg}$ to a chilli sample Sudan I free).

For the extraction procedure $\mathrm{B}$, the detection limit was 60 $\mu \mathrm{g} / \mathrm{kg}$ and the quantitation limit is $180 \mu \mathrm{g} / \mathrm{kg}$ (i.e., 3 times the detection limit). Recovery values ranged between 65 and $75 \%$ and CV\% between 4 and 2\% (spiking made at levels between 50 and $10 \mathrm{mg} / \mathrm{kg}$ to an oven baked sample Sudan I free).

The calibration curve was linear $\left(R^{2}=0.9983\right)$ in the range 0.098 to $9.778 \mathrm{mg} / \mathrm{L}$, monitoring the TIC area counts $(\mathrm{m} / z 248$, 249). For high levels of Sudan I in the sample, diluting (1:10 or 1:100) the extract before injection is preferable, to avoid detector saturation.
Figure 4 shows the HPLC/APCI-MS elution profiles of (a) standard solution at $684 \mu \mathrm{g} / \mathrm{L}$, (b) extract of a sample of "taralli", obtained with the procedure B and diluted 10 times, and (c) standard solution at $98 \mu \mathrm{g} / \mathrm{L}$. The amount of Sudan I in the sample of "taralli" was $968 \mu \mathrm{g} / \mathrm{kg}$, value corrected for dilution factor and recovery.

To conclude, the HPLC/APCI-MS method is suitable for identification of peak identity of Sudan I in chillies and in ovenbaked products and may be considered useful for Sudan I determination also at very low levels. The assessment of the use of methanol as extraction solvent on other foods containing chilli, such as tomato sauces, sausages, and other matrixes is ongoing, and at the present, validation data are in progress. First results give evidence of higher recovery values for using methanol. In this way, the method is useful for general application.

\section{ACKNOWLEDGMENT}

Thanks are due to G. Andreoli and M. Seghezzi and A. Rosa for technical collaboration.

\section{LITERATURE CITED}

(1) Commission Decision (E. C.) n.460/2003 of 20 June 2003. On emergency measures regarding hot chilli and hot chilli products. Off. J. Eur. Union, L. 2003, 154, 114. 
(2) Pupin, A. M.; Dennis, M. J.; Toledo, M. C. F. HPLC analysis of carotenoids in orange juice. Food Chem. 1999, 64, 269-275.

(3) Philip, T.; Chen, T.-S.; Nelson, D. B. Detection of adulteration of California orange juice concentrates with externally added carotenoids by liquid chromatography. J. Agric. Food Chem. 1989, 37, 90-95.

(4) Quackenbush, F. W.; Smallidge, R. L. Non aqueous reverse phase liquid chromatographic system for separation and quantitation of pro vitamins A. J. Assoc. Off. Anal. Chem. 1986, 69, 767772.

(5) Private communication from ARPA (Regional Agency for Prevention and Environment). Unpublished.

(6) O. S. H. A. (Occupational Safety \& Health Administration). Chemical Sampling Information. http://www.osha.gov/dts/chemicalsampling/data/CH_268420.html

(7) Chen, Q.-c.; Mou, S.-f.; Hou, X.-p.; Riviello, J. M.; Ni, Z.-m. Determination of eight synthetic food colorants in drinks by highperformance ion chromatography. J. Chromatogr. A 1998, 827, $73-81$.
(8) Capità, F.; Capitàn-Vallvey, L. F.; Fernàndez, M. D.; de Orbe, I.; Avidad, R. Determination of colorant matters mixtures in food by solid-phase spectrophotometry. Anal. Chim. Acta 1996, 331, 141-148.

(9) FSA (Food Standars Agency). Method 145a. Collaborative trial 145 of a method for the detection and determination of Sudan I in chilli products by HPLC. www.food.gov.uk/multimedia/pdfs/ Sudan145a.pdf

(10) FSA (Food Standars Agency). Method 145b. Collaborative trial 145 of a method for the detection and determination of Sudan I in chilli products by HPLC. www.food.gov.uk/multimedia/pdfs/ 145b.pdf

Received for review October 24, 2003. Revised manuscript received November 28, 2003. Accepted November 30, 2003.

JF030721S 